\title{
Prevalence and pattern of traditional medicine use among pregnant women on highly active anti-retroviral therapy in the University of Port Harcourt Teaching Hospital, Port Harcourt, Rivers State
}

\author{
Ezinne C. Iwunze ${ }^{1}$, Ibitein N. Okeafor ${ }^{2}$ \\ ${ }^{1}$ Department of Community Medicine, University of Port Harcourt Teaching Hospital, Port Harcourt, Rivers State, Nigeria \\ ${ }^{2}$ Research Support Unit, Eagles Watch Research Centre and Care, Port Harcourt, Rivers State, Nigeria
}

\begin{abstract}
Introduction: Traditional medicine use is considered as the primary source of health care in many African settings. In the present human immunodeficiency virus (HIV) pandemic, affected individuals often employ its use as coping strategies. This study aimed to determine the prevalence and pattern of traditional medicine use among HIV-positive pregnant women on highly active anti-retroviral therapy (HAART) in the University of Port Harcourt Teaching Hospital (UPTH).

Material and methods: The study was a cross-sectional study involving pregnant women on HAART in UPTH, Rivers State, Nigeria. Data on the socio-demographic characteristics, pattern, and reasons for traditional medicine use were obtained through validated interviewer-administered questionnaire. Descriptive statistics were used in summarizing data, while $\chi^{2}$ for homogeneity was used to compare the difference in proportion of traditional medicine use.

Results: The study had a total of 113 pregnant women on HAART, with mean age $31.6 \pm 4.1$ years. Prevalence of traditional medicine use was $11.5 \%(n=13)$. The difference in proportion of traditional medicine use across the respondents was statistically significant $(p<0.05)$. Majority $(84.6 \%)$ of them did not disclose traditional medicine use to their physicians. Higher proportion of them $(76.9 \%)$ believed that traditional medicine boosted their immunity, while a lower proportion of $7.7 \%$ believed that it could cure HIV.

Conclusions: Traditional medicine use among HIV-positive pregnant women on HAART is not uncommon. Hence, there is a need for public health enlightenment on the prevention of traditional medicine use amongst them, while advocating for further studies to investigate the chemical components of these traditional remedies.
\end{abstract}

HIV AIDS Rev 2018; 17, 3: 197-202

DOI: https://doi.org/10.5114/hivar.2018.78492

Key words: HIV, pregnant women, Nigeria, antiretroviral drugs, traditional medicine.

Address for correspondence: Dr. Ibitein N. Okeafor, Research Support Unit, Eagles Watch Research Centre and Care, 107 East-West Road, 50001 Port Harcourt, Rivers State, Nigeria, phone: +2348155241020 ,

e-mail: eagleswatchresearch@gmail.com
Article history:

Received: 26.10.2017

Received in revised form: 24.12.2017

Accepted: 02.01.2018

Available online: 15.08.2018
International Journal of HIV-Related Problems

HIV \& AIDS

R e v i e w 


\section{Introduction}

The long history of the use of traditional remedies, which includes trans-generational experiences, has to some degree validated claims of their safety and efficacy [1]. However, to ensure evidence-based approach in traditional medicine, the use and practice require further scientific research to provide additional substantiation of their safety and efficacy [1]. The use of traditional medicine is also on the increase in industrialized countries, and it is estimated that $30-50 \%$ of medications being used by individuals are traditional preparations [1]. According to the World Health Organization (WHO) fact sheet on traditional medicine, its use is widespread in countries in Africa, Asia, and Latin America, and this is employed to meet some of their primary health care needs [2]. It is estimated that in Africa, up to $80 \%$ of the population use traditional medicine for primary health care [2].

Traditional medicine use in pregnancy is widespread in Africa despite orthodox medical prescriptions [3]. Westfall showed that traditional medicines and other alternative therapies are some of the many coping strategies that women employ in the first few months of pregnancy to combat nausea and vomiting [4]. The use of traditional medicine in pregnancy has aroused concerns as these may have some adverse effects on pregnancy, interaction with prescribed medications, and potentially serious complications for the fetus $[5,6]$. Despite a seemingly widespread use, little is known about patterns of traditional medicine use [7]. There is a scarcity of research on the pattern and reasons for traditional medicine use among human immunodeficiency virus (HIV)-positive pregnant women receiving antiretroviral therapy (ART). This study therefore aims to identify the prevalence, pattern, and reasons for traditional medicine use among HIV-infected pregnant women receiving highly active antiretroviral therapy (HAART) in a low-middle income country.

\section{Material and methods}

\section{Study area}

The study was carried out in Obio/Akpor local government area in Rivers State (one of the thirty-six states in Nigeria), located in the Southern part of the country and is embedded in the Niger Delta Region. The local government has its headquarters at Rumuodomaya with a population of 462,350 and a density of $1,778.3 \mathrm{inh} / \mathrm{km}^{2}$ [8].

\section{Study center}

The University of Port Harcourt Teaching Hospital (UPTH), a 650-bedded tertiary health facility was the study center. UPTH has sixteen clinical departments, providing out-patient, in-patient, and emergency services. It is located along the East-West Road, and adjacent to the University of Port Harcourt. It serves as a center covering a large catchment area including the neighbouring states. The antenatal clinic of UPTH operates on weekdays, with an average of 500 patients weekly. The prevention of mother to child transmission (PMTCT) services carried out in the clinic include HIV counseling and testing (HCT), adherence counseling, health education on family planning, and infant feeding. At the time of the study, about 115 patients were on HAART, and average of 10 patients were seen weekly (Monday to Friday).

\section{Study design and population}

The study was a descriptive cross-sectional study. The study population comprised of pregnant women on HAART who gave consent to be part of the study.

\section{Sample size calculation}

The sample size was determined based on Cochran's formula [9] to estimate the minimum sample size for proportions. A prevalence of traditional medicine use among pregnant women from a similar study in Nigeria was 31.4\% [10]. The formula for the final sample estimate when the entire population is less than 10,000 was employed [11], and a minimum sample size of 113 pregnant women on HAART was determined. An average of 2 patients per day was seen at the PMTCT clinic, so every eligible pregnant woman was sampled.

\section{Data collection}

Data was collected from September 2014 to November 2014. Data on the socio-demographic variables (age, marital status, gravidity, and gestational age) and traditional medicine use was obtained using an anonymous interviewer-administered questionnaire, which was content-validated and semi-structured.

\section{Statistical analysis}

The IBM statistical package for social sciences (SPSS) version 20 software was used for data analysis. Age was summarized using mean and standard deviation. Traditional medicine use and its pattern were presented as frequencies and proportions. The difference in proportion of traditional medicine use by respondents was compared by $\chi^{2}$ for homogeneity and statistical significance set at 0.05 .

\section{Ethical consideration}

Ethical approval was granted by the Research and Ethics Committee of the University of Port Harcourt Teaching Hospital, Rivers State. Written informed consent was obtained from the respondents prior to inclusion in the study. Anonymity was maintained in the course of data management and information obtained were held confidential. 
Table 1. Demographic characteristics of respondents $(n=113)$

\begin{tabular}{|c|c|c|}
\hline Variable & $n$ & $\%$ \\
\hline \multicolumn{3}{|l|}{ Age (years) } \\
\hline $25-34$ & 89 & 78.8 \\
\hline $35-44$ & 24 & 21.2 \\
\hline \multicolumn{3}{|l|}{ Marital status } \\
\hline Married & 109 & 98.5 \\
\hline Widowed & 4 & 1.5 \\
\hline \multicolumn{3}{|l|}{ Gestational age } \\
\hline $1^{\text {st }}$ trimester & 6 & 5.3 \\
\hline $2^{\text {nd }}$ trimester & 40 & 35.4 \\
\hline $3^{\text {rd }}$ trimester & 67 & 59.3 \\
\hline \multicolumn{3}{|l|}{ Gravidity } \\
\hline Gravida 1 & 39 & 34.5 \\
\hline Gravida 2-4 & 71 & 62.8 \\
\hline Gravida $\geq 5$ & 3 & 2.7 \\
\hline
\end{tabular}

Table 2. Traditional medicine use in the index $\mathrm{P}=$ pregnancy

\begin{tabular}{l|c|c}
\hline Traditional medicine use & $n$ & Frequency \\
\hline Yes & 13 & 11.5 \\
\hline No & 100 & 88.5 \\
\hline Total & 113 & 100 \\
\hline
\end{tabular}

$\chi^{2}$ for homogeneity $=66.982 ; d f=1 ; p$-value $=0.0001^{*}$

${ }^{*}$ Statistically significant

\section{Results}

The study had a total of 113 HIV-positive pregnant women who were on HAART. The mean age of the women was $31.6 \pm 4.1$ years. The characteristics of patients are presented in Table 1 . Higher proportions of women were married $(98.5 \%)$, in third trimester $(59.3 \%)$, and had gravidity of $2-4(62.8 \%)$.

Prevalence of traditional medicine use in index pregnancy was $11.5 \%(n=13)$. These medicines were used orally. Chi-square coefficient $\left(\chi^{2}\right)$ for homogeneity showed that the difference in proportions across traditional medicine use among HIV-positive pregnant women was statistically significant $(p=0.0001)$.

A herb called moringa was the main form of traditional medicine $(53.8 \%)$ used by HIV-infected pregnant women as shown in Figure 1. Tables 2 and 3 show the pattern of traditional medicine use among HIV-positive pregnant women. Concerning frequency of traditional medicine use, the highest proportion of the respondents (46.2\%) used traditional medicine daily. Majority $(84.6 \%)$ of them did not disclose traditional medicine use to their physicians. A higher proportion (53.8\%) of the respondents reported that traditional medicine use was influenced by a family member. A frequency of $61.5 \%$ of patients sourced these
Table 3. Pattern of traditional medicine use

\begin{tabular}{|c|c|c|}
\hline Variables $(n=13)$ & $n$ & Frequency (\%) \\
\hline \multicolumn{3}{|l|}{ Frequency of traditional medicine use } \\
\hline Many times in a day & 4 & 30.8 \\
\hline Once daily & 6 & 46.2 \\
\hline Weekly & 2 & 15.4 \\
\hline Occasionally (less than weekly) & 1 & 7.6 \\
\hline \multicolumn{3}{|c|}{ Disclosure of traditional medicine use to doctor } \\
\hline Yes & 2 & 15.4 \\
\hline No & 11 & 84.6 \\
\hline \multicolumn{3}{|l|}{ Is traditional medicine use beneficial? } \\
\hline Yes & 11 & 84.6 \\
\hline No & 2 & 15.4 \\
\hline \multicolumn{3}{|c|}{ Who advised you to use traditional medicine } \\
\hline Family member & 7 & 53.8 \\
\hline Self & 6 & 46.2 \\
\hline \multicolumn{3}{|l|}{ Source of traditional medicine } \\
\hline Herbalist & 2 & 15.4 \\
\hline Pharmacy & 2 & 15.4 \\
\hline Self-made & 1 & 7.7 \\
\hline Traditional medicine dealer & 8 & 61.5 \\
\hline \multicolumn{3}{|l|}{ Is traditional medicine harmful to baby } \\
\hline Yes & 0 & 0.0 \\
\hline No & 13 & 100.0 \\
\hline
\end{tabular}

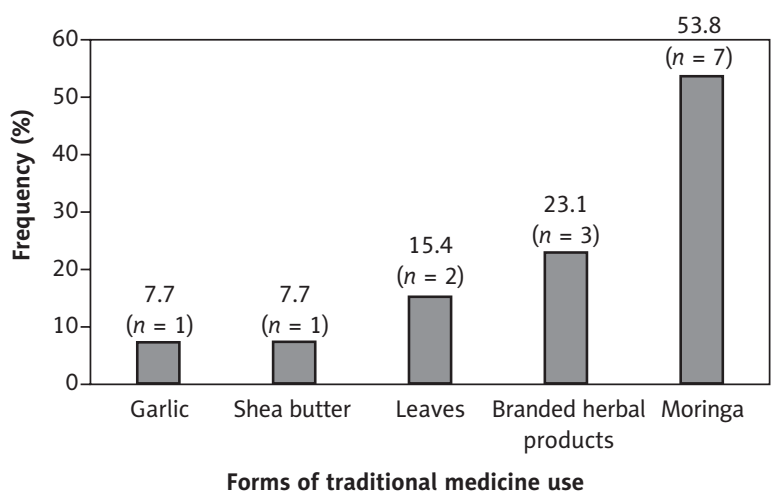

Fig. 1. Forms of traditional medicine (some of women used more than one form of traditional medicine)

drugs from a traditional dealer. All the respondents reported that these preparations had no harmful effects to the baby.

Figure 2 shows the reasons for traditional medicine use among HIV-positive pregnant women. Majority (76.9\%) believed that traditional medicine use boosts their immunity, while a much lower proportion of $7.7 \%$ of the respondents believed that traditional medicine could cure HIV. 


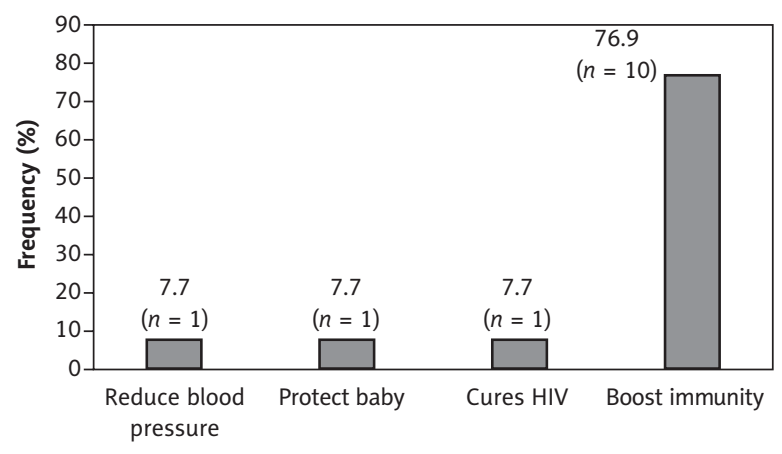

Reasons of traditional medicine use

Fig. 2. Reasons for traditional medicine use

\section{Discussion}

Traditional medicine use among HIV patients in developing countries is widespread and particularly used as supplements for antiretroviral drugs [12]. Widespread use originates from the belief that they are natural and safe [12] The practice often goes unnoticed, stigmatized and linked with non-adherence to ARV therapy [12]. However, these traditional medicines contain pharmacological active ingredients, which have the potential to harm and interact with conventional drug preparations [13].

This study revealed that a tenth of the respondents used traditional medicine in the index pregnancy. This observation is in keeping with a similar study by Awodele et al. on the use of traditional medicine among HIV patients on ARV in a Nigerian tertiary hospital [13]. Furthermore, the prevalence observed in this study is consistent with a similar cross-sectional study on the pattern of drug use in Benin City, Nigeria, which showed also that about a tenth of mothers used herbal preparations [14]. Contrary to the proportion of pregnant women on ARV, who use traditional medicine as observed in this study is a higher proportion from similar studies $[10,15]$ in Northern Nigeria on pregnant women receiving ante-natal care, who used herbal medicine during their pregnancies.

The low prevalence of traditional medicine use obtained in this study may be due to continuous adherence counseling offered to patients to avoid taking herbal medicines with antiretroviral drugs because of potential harm to their babies and possible interactions with prescribed drugs. However, similar studies $[16,17]$ in Norway and Australia showed a sharp contrast in the proportion of traditional medicine use compared to the prevalence observed in this study. Furthermore, findings from a Finnish study [18] are comparable with the prevalence of $11.3 \%$ reported in our study.

In this study, herbs were the main form of traditional medicine used by the HIV-infected pregnant women. This finding compares favorably with other African studies $[13,19,20]$. Also, findings on the forms of traditional medicine use from an Australian cross sectional study [17] on the prevalence of herbal medicine use in a group of pregnant women are consistent with that observed in this study.

Concerning the frequency of traditional medicine use, the finding of more women using it daily in present study is consistent with another study in Southern Nigeria [13]. This finding may be due to long standing use of these drugs, pressure from family, or as a result of side effects of antiretroviral drugs. These traditional remedies could be potentially harmful to the mother and the developing fetus. Further research on these herbal preparations is needed to discover the active ingredients, extract them, determine their optimal doses and the best route of administration, in order to derive maximum benefits from this therapy.

It was noted that majority of these antenatal clients did not disclose traditional medicine use to their physicians. This observation is consistent with other studies [20, 21]. This finding may be due to fear of stigmatization by their health care providers, which might interfere with their professional relationships. It is of utmost priority that a more open and effective patient-physician communication be encouraged. Also, health care professionals should routinely enquire about traditional medicine use in both HIV and pregnant patients as a part of their medical interview and clinical assessments during antenatal visits. This will help to avoid possible serious adverse effects and negative interactions between using antiretroviral drugs and traditional medicine in pregnancy.

This study found that a significant proportion of the study participants reported that traditional medicine use was influenced by a family member. This finding is in accordance with similar studies $[19,22]$. Proper adherence counseling should be reinforced, and patients should be encouraged to take full responsibility for their health during pregnancy, as the results of our study showed that families of pregnant women were responsible for decision on traditional medicine use.

HIV-positive antenatal patients on antiretroviral drugs should however be properly educated on possible adverse effects caused by these preparations, harming the patients and their developing fetuses. It was observed in this study that majority of participants sourced these drugs from a traditional dealer. This finding compares favorably with that observed by Hughes et al. [20]. Policies to regulate the sale of these drugs after a review by the food and drug agencies should be put in place. Furthermore, in our communities, these traditional dealers are highly valued and are often consulted for the procurement of traditional preparations for different health care needs. They should therefore be recognized, possibly incorporated into health initiatives, and avenues for interaction with these traditional dealers should be created in order to address selective health needs of these clients to guarantee the success of PMTCT programmes.

It was observed that all the antenatal patients that used traditional medicine in this study reported that these preparations had no harmful effects to the baby. This finding com- 
pares favorably with a similar study, which showed that only a small proportion believed that traditional herbs can hurt the unborn baby [21]. This finding is also consistent with a similar study by Fakeye et al. [15]. In sharp contrast is a similar study, which showed that a significant proportion of the participants judged traditional medicine use as being dangerous to both mother and the fetus [10]. These findings observed in this study may be due to the belief that these products are natural and therefore safe. However, the need for studies to investigate the contents of these commonly used traditional medicines are advocated. In the same vein, there should be increased emphasis on the dangers of traditional medicine use in pregnancy due to the potential to interact with antiretroviral drugs, thereby possibly reducing their efficacy to prevent HIV transmission from mother to child.

It was also observed in this study that belief in additional efficacy to boost their immunity was implicated in traditional medicine use. This is consistent with an Ugandan study [19]. A small proportion of participants in this study believed that traditional medicine could cure HIV. This observation is in keeping with earlier studies $[15,21,23]$. This calls for proper education on the pathogenesis of HIV and its management among pregnant women during antenatal care visits.

\section{Limitations}

The prevalence of traditional medicine reported in present study could be underestimated, as some pregnant women may be apprehensive in admitting the use of traditional medicine, since these products are possibly perceived negatively by the health care providers. However, in order to ensure validity of our findings, they were requested to answer truthfully, ensuring that responses provided will not affect any of services received at a health facility. Another limitation is the non-generalizability of the study because it is facility-based and the fact that the chemical components of the traditional medicines were not investigated. The authors could not follow-up these women using traditional remedies due to the cross-sectional nature of the study. Nonetheless, the index study focused on the prevalence and pattern of traditional medicine use among HIV-positive pregnant women and our findings highlight the need for further studies on the predictors of traditional medicine use as well as the influence of traditional medicine use on perinatal outcome among these women.

\section{Conclusions}

The prevalence and pattern of traditional medicine use observed among HIV-positive pregnant women on HAART in this study reveals that traditional medicine use among them is not uncommon. Hence, issues regarding safety, efficacy, and quality of traditional medicine among patients need to be thoroughly investigated.

\section{Conflict of interest}

The authors declare no potential conflicts of interest with respect to the research, authorship, and/or publication of this article.

\section{References}

1. World Health Organization (WHO). General guidelines for methodologies onresearch and evaluation of traditional medicine. WHO, Geneva 2000.

2. World Health Organization (WHO). Traditional medicine, fact sheet no 134. Available at: http://www.Who.Int/mediacentre/factsheets/fs134/en/ (Assessed: 5 July 2016).

3. Malan DF, Neuba DF. Traditional practices and medicinal plants use during pregnancy by Anyi-Ndenye women (Eastern Côte d'Ivoire). Afr J Reprod Health 2011; 15: 85-93.

4. Westfall RE. Use of anti-emetic herbs in pregnancy: women's choices, and the question of safety and efficacy. Complement Ther Nurs Midwifery 2004; 10: 30-36.

5. Chuang CH, Doyle P, Wang JD, et al. Herbal medicines used during the first trimester and major congenital malformations. Drug Saf 2006; 29: 537-548.

6. Pinn G, Pallett L. Herbal medicine in pregnancy. Complement Ther Nurs Midwifery 2002; 8: 77-80.

7. Gardiner P, Graham R, Legedza AT, Ahn AC. Factors associated with herbal therapy use by adults in the United States. Altern Ther Health Med 2007; 13: 22-29.

8. National Population Commision (NPC). Obio/Akpor (Local Government Area, Nigeria) - population statistics. 2006. Available at: www. Citypopulation.De/php/nigeria-admin.Php?Adm2.D=nga033015.

9. Cochran WG. Sampling techniques. $3^{\text {rd }}$ ed. John Wiley \& Sons, New York 1977; 75-76.

10. Tamuno I, Omole-Ohonsi A, Fadare J. Use of herbal medicine among pregnant women attending a tertiary hospital in Northern Nigeria. Int J Gynecol Obstet 2011; 15; DOI: 10.5580/2932.

11. Araoye MO. Research methodology with statistics for health and social sciences. Nathadex Publishers, Ilorin 2004; 119-120.

12. Banda Y, Chapman V, Goldenberg RL, et al. Use of traditional medicine among pregnant women in Lusaka, Zambia. J Altern Complement Med 2007; 13: 123-128.

13. Awodele O, Olayemi O, Adeyemo AT, et al. Use of complementary medicine amongst patients on antiretroviral drugs in an HIV treatment centre in Lagos, Nigeria. Curr Drug Safety 2012; 7: $120-125$.

14. Gharoro E, Igbafe A. Pattern of drug use amongst antenatal patients in Benin City, Nigeria. Med Sci Monit 2000; 6: 84-87.

15. Fakeye TO, Adisa R, Musa IE. Attitude and use of herbal medicines among pregnant women in Nigeria. BMC Complement Altern Med 2009; 9: 53.

16. Nordeng H, Havnen GC. Use of herbal drugs in pregnancy: a survey among 400 Norwegian women. Pharmacoepidemiol Drug Saf 2004; 13: 371-380.

17. Forster DA, Denning A, Wills G, et al. Herbal medicine use during pregnancy in a group of Australian women. BMC Pregnancy Childbirth 2006; 6: 21.

18. Hemminki E, Mäntyranta T, Malin M, Koponen P. A survey on the use of alternative drugs during pregnancy. Scan J Public Health 1991; 19: 199-204.

19. Langlois-Klassen D, Kipp W, et al. Use of traditional herbal medicine by AIDS patients in Kabarole District, western Uganda. Am J Trop Med Hyg 2007; 77: 757-763.

20. Hughes G, Puoane T, Clark B, et al. Prevalence and predictors of traditional medicine utilization among persons living with AIDS (PLWA) on antiretroviral (ARV) and prophylaxis treatment in both rural and 
urban areas in South Africa. Afr J Tradit Complement Altern Med 2012; 9: 470-484.

21. Peltzer K, Phaswana-Mafuya N, Treger L. Use of traditional and complementary health practices in prenatal, delivery and postnatal care in the context of HIV transmission from mother to child (PMTCT) in the Eastern Cape, South Africa. Afr J Tradit Complement Altern Med 2009; 6: 155-162.

22. Pallivalappila AR, Stewart D, Shetty A, et al. Complementary and alternative medicine use during early pregnancy. Eur J Obst Gynenol Reprod Biol 2014; 181: 251-255.

23. Furler MD, Einarson TR, Walmsley S, et al. Use of complementary and alternative medicine by HIV-infected outpatients in ontario, canada. AIDS Patient Care STDs 2003; 17: 155-168. 